Research Article

\title{
Research on Real Working Condition Simulation and Performance Test of Wind Power Main Bearing Based on Test Bench
}

\author{
Guodong Zhai (D), Xujie Qin, and Xing Yang \\ School of Mechanical Electronic \& Information Engineering, China University of Mining \& Technology-Beijing, \\ Beijing 100083, China \\ Correspondence should be addressed to Guodong Zhai; zgd@cumtb.edu.cn
}

Received 24 November 2020; Revised 29 January 2021; Accepted 7 April 2021; Published 16 April 2021

Academic Editor: Bekir Sahin

Copyright (C) 2021 Guodong Zhai et al. This is an open access article distributed under the Creative Commons Attribution License, which permits unrestricted use, distribution, and reproduction in any medium, provided the original work is properly cited.

As a renewable energy source, wind energy has received more and more attention, and the wind power industry has also been advocated and developed by countries all over the world. In the production and use of wind turbines, the design and manufacturing technology of wind turbine bearings is very important. In order to ensure the reliable operation of the wind power main bearing after installation and realize the longest life of it, this paper designs a bearing test bench that can test the performance of the wind power main bearing. It can analyze the temperature, displacement, load, and moment of the key parts of the $5 \mathrm{MW}$ wind power main shaft bearing. The solid modeling of the experimental platform was carried out using the 3D modeling software SolidWorks. Hydraulic loading system and test monitoring system are designed to realize the drive and control of the test bench. Through the established mathematical model, the central load of the hub is converted into the axial cylinder load and the radial cylinder load of the test bench to simulate the actual working conditions of the tested bearing. The test results show that the test bench meets various loading requirements and can reliably complete the task of testing wind power main bearings.

\section{Introduction}

With the consumption of energy, the deteriorating environmental problems, and the increasing demand for electricity, wind energy, as a renewable clean energy source, has received more and more attention due to its environmental protection, low cost, and other advantages. Wind power has become one of the most promising and economically beneficial energy sources [1-5]. In the past ten years, it had the largest demand and growth between all renewable energy sources [6]. Recent surveys show that the annual growth rate of installed wind power capacity is about $30 \%$ [7], and the global average wind power installed capacity coefficient has increased from less than $22 \%$ in 2010 to more than $24 \%$ in 2017. In 2017, the global installed wind power capacity increased to $539 \mathrm{GW}$ [8]; it is estimated that the total capacity will exceed $800 \mathrm{GW}$ by $2021[9,10]$. The wind turbine is the core key equipment of the entire wind power system. Its working environment is usually in extreme harsh environments such as desert, sand, humidity, corrosion, etc., which seriously affects its operation safety and maintenance guarantee [11]. Therefore, wind turbines must have high reliability. Imperfect design and installation detection technology will reduce the overall reliability of wind turbines $[12,13]$. So, the state to carry out monitoring studies of wind turbines, wind turbine to grasp the operational status and ensure safe, and efficient wind turbine power generation operation is important [14].

As the core key equipment of the entire wind power system, wind turbines have attracted the attention of many researchers for their power generation efficiency and failure detection of key components. For example, Sun et al. [15] proposed an ANN-wake-up power model. For a given wind speed, wind direction, and yaw angle, the model can estimate the total power generation of the wind turbine. Subsequently, the genetic algorithm was used to apply the model to optimize the yaw angle to minimize the impact of the wake on the entire wind farm. Aiming at the fact that 
traditional particle swarm optimization technology cannot solve the problem of nonlinearity and uncertainty of the system, Iqbal et al. [16] proposed a particle swarm optimization algorithm (PSO) to calculate the optimal parameters of the controller. The Lyapunov function was used to verify system's stability. Compared with the traditional PSO method, the proposed PSO technology can generate higher output power and limit the rotor speed and mechanical torque, thereby effectively adjusting the pitch angle of the wind turbine. Han et al. [17] proposed a design method of IPC's fuzzy logic controller to optimize the trade-off between several control objectives, reduce the fatigue load of the wind turbine, and adjust the output power. Aiming at the centrifugal load and gravity load on the wind turbine blades to reduce the power output and the equipment life, Iqbal et al. [18] proposed a fuzzy model-based pitch angle controller: the fuzzy logic controller encounters the system linearity works very efficiently, while model predictive controllers can help the system become more stable and efficient. The load impact of the wind turbine is reduced, and the extracted power output is maximized. Guo et al. [19] proposed a physical domain model for bearing reliability evaluation and prognosis of wind power bearings. It uses SCADA data and wind power plant failure records to predict the failure probability of each gearbox bearing in each wind turbine in the power plant. Rezamand et al. [20] proposed a comprehensive prediction method based on signal processing and adaptive Bayes algorithm to predict the RUL of various faulty bearings in wind turbines. Kong et al. [21] proposed a sparse representation classification (DDL-SRC) framework based on discriminant dictionary learning for intelligent planetary bearing fault identification. Chen et al. [22] proposed a method for fault diagnosis of bearing corrosion of doubly fed wind turbines based on stator current analysis. $\mathrm{Xu}$ et al. [23] proposed a new scheme for bearing fault detection through Quantile Regression Neural Network (QRNN). Guo et al. [24] proposed a new method based on data-driven multiscale dictionary construction, which can more effectively extract bearing fault features from the measured signal. Gu et al. [25] proposed an adaptive SR algorithm based on Quantum Particle Swarm Optimization (QPSO) and a frequency conversion based on frequency information exchange (FIE) wind turbine bearing fault diagnosis method. Wang et al. [26] used the fault diagnosis method of wavelet transform, the health index algorithm to fuse the extracted features, and the empirical physical knowledge and statistical model based on the Bayesian framework realized bearing fault diagnosis and life prediction. Nath et al. [27] proposed a new multicandidate lowlatency detection algorithm based on the unique nature of wind turbine bearing faults. Han et al. [28] used fatigue life analysis to determine the health status of the blade bearing in order to diagnose the fault type of the blade bearing of the wind turbine.

The main bearing of wind power is at the most critical position in the bearing system of the wind turbine. It must be ensured that it has a high load-bearing capacity and a long service life during the design and manufacturing process. As the most effective method for testing bearings, bearing test benches can test and analyze key parts of bearings to prevent failures, so that it can meet the requirements of high reliability and long life. Therefore, it has attracted the attention of many researchers and research institutions. For example, Huarui Wind Power Technology Co., Ltd. [29] has developed a wind turbine variable pitch bearing experimental equipment, which can simulate the actual working conditions of the bearing; Xiangdian Wind Energy Co., Ltd. [30] designed a wind power variable pitch bearing test bench. It can test the working conditions, noise, displacement, bearing life, etc., of the bearing after loading and guide the production of the enterprise. The pitch bearing test machine researched by Luoyang LYC Bearing Company [31] can simulate actual working conditions for loading, obtain the friction torque curve during the entire loading process, and judge whether the bearing can meet the predetermined life requirements. The wind turbine yaw test mechanism and the wind turbine test bench researched by Sany Electric Co., Ltd. [32] can perform the yaw test synchronously while the wind turbine is being driven. It saves a lot of time and improves work efficiency. At the same time, it is easy to install and save space for testing. ROTHE ERDE [33] has developed a slewing bearing test bench specifically for wind power slewing bearings, which can detect the comprehensive performance of the bearing raceway. SKF [34] has established a bearing test bench in Germany, which can test the friction performance and life of $3 \mathrm{MW}$ wind turbine bearings. The slewing bearing test bench developed by the LGMT laboratory in France [35] can analyze the load distribution of the slewing bearing under static load. The high-speed shaft test bench and planetary test bench researched by Kock's et al. laboratory [36] can use the BRT method to simulate the most realistic load situation on the spot to perform fault testing on the bearing, thereby improving the quality of the bearing and reducing the failure rate. Japan TNT [37] built the world's largest wind turbine bearing test machine. It has a remote intelligent condition monitoring system, which can perform high-strength durability tests and complete diagnostic analysis on various bearings.

This paper believes that the load simulation function of the traditional wind power bearing test bench is poor, and the test control system cannot automatically collect and process various test data, which seriously affects the accuracy of the data, and cannot well evaluate whether the comprehensive performance of the wind power main bearing can be used. Therefore, it is necessary to study a new type of large-scale wind turbine bearing comprehensive performance test bench. This paper systematically introduces the research and development of the wind turbine main shaft bearing test bench from the aspects of solid modeling, loading system, test control system, and simulation loading. It can analyze the temperature, displacement, load, and other data of key parts of the $5 \mathrm{MW}$ wind power main shaft bearing, simulate the combination of the huge axial force, radial force, and overturning moment of the wind power turntable bearing, and detect the unloaded and loaded startup performance in the state, automatic detection and analysis of the vibration characteristics of the slewing bearing during operation, and evaluation of the service life of 
the slewing bearing to meet the requirements of the test wind power main bearing. The rest of this paper is structured as follows. In Section 2, the main theory and working principle of the test bench are introduced. In Section 3, the method steps of the performance test of the wind power main bearing based on the test bench are introduced. In Section 4, the detailed design steps and experimental results of the test bench are introduced. In Section 5, the innovation of this paper compared with the previous technology is introduced. Finally, the main conclusions from this study are drawn in Section 6.

\section{Subject Theory}

2.1. Test Bench Function Analysis. Wind power main shaft bearing is the core part of wind turbine; it is a single-row tapered roller bearing, which is mainly subjected to axial force, radial force, and overturning moment. Therefore, the bearing testing machine must test within the specified load range and obtain accurate bearing test data, so the test bench must meet the following technical requirements:

(1) The control system should be closed loop control

(2) The test bench has two control functions: automatic loading and manual loading

(3) Able to automatically collect and process data to obtain the temperature, torque, displacement, and other data of the test bearing

(4) Able to statically and dynamically load the main bearing of a $5 \mathrm{MW}$ large wind turbine

(5) After the test bearing is installed, the inclination angle of the bearing axis and the horizontal plane is $5^{\circ}$

2.2. Test Bench Loading Requirements. According to the load analysis of the actual spindle bearing, the main parameters of the testing machine are as follows:

(a) Single-row tapered roller bearings, with an outer diameter of $2500 \mathrm{~mm}$, an inner diameter of $2000 \mathrm{~mm}$, and a height of $320 \mathrm{~mm}$

(b) Maximum bearing deformation $5 \mathrm{~mm}$

(c) Bearing speed 0-30 r/min and stepless speed regulation

(d) Axial load $\geq 12000 \mathrm{kN}$, radial load $\geq 4000 \mathrm{kN}$, and overturning moment $\geq 30000 \mathrm{kNm}$

(e) Each cylinder can be loaded independently

2.3. Working Principle of Test Bench. According to the actual working conditions of the wind power main shaft, the main structure of the wind power main shaft bearing test machine developed includes 4 modules including test bearing, drive system, loading system, and test monitoring system; its working principle is shown in Figure 1. When working, test the pairing of two wind power singlerow tapered roller bearings and install them on the main body of the testing machine, and it is connected to the loading system. The hydraulic loading system is connected to the main body of the testing machine through the oil cylinder, and the load is changed through the PLC control of the overflow valve; it can apply axial load and radial load to wind turbine bearings according to the test requirements to simulate the actual bearing conditions of the bearing. The test monitoring system includes a PLC control system and a computer monitoring system, and data transmission is carried out between the two through TCP communication. It can control and adjust the pressure of the load system and can get the temperature, load, torque, displacement, and other data fed back by the sensor, store it in its own server, and transmit these data to the computer monitoring system client through TCP communication. The test monitoring system can accurately test and process various data to determine whether the wind turbine bearing can meet the requirements of use. Through the precise coordination of various systems, the wind turbine main shaft bearing testing machine can run stably.

\section{Design Methodology}

In this study, the wind power main bearing test bench was used to simulate the real working environment of the wind power generator to test the comprehensive performance of the wind power main bearing. The testing process is mainly deployed through six processes.

Step 1. Three-dimensional modeling of test bench: The structure of the experimental platform was designed using the $3 \mathrm{D}$ modeling software SolidWorks, and the whole machine was modularized using a reasonable model segmentation method.

Step 2. Design of hydraulic loading system: The hydraulic loading system can realize the combination of various loads and is used to simulate the real working conditions of wind power main bearings.

Step 3. Design of hydraulic drive system: The hydraulic drive system can ensure that the test bearing performs various performance tests under loading conditions.

Step 4. The design of the test monitoring system: A measurement and control system for wind turbine bearing testing machine based on LabVIEW and PLC is designed, which can control the size and direction of the load, automatically collect test data, and perform accurate analysis.

Step 5. Analysis of mechanical model of wind power bearing: Using the relevant analysis method of the space force system in engineering mechanics, the center load of the hub is converted to the reference plane of the tested bearing, and the force system conversion mathematical model is established.

Step 6. Performance test of wind power main bearing: Install the test bearing on the test bench for simulated loading to determine whether the comprehensive performance of the test bearing meets the established requirements. 


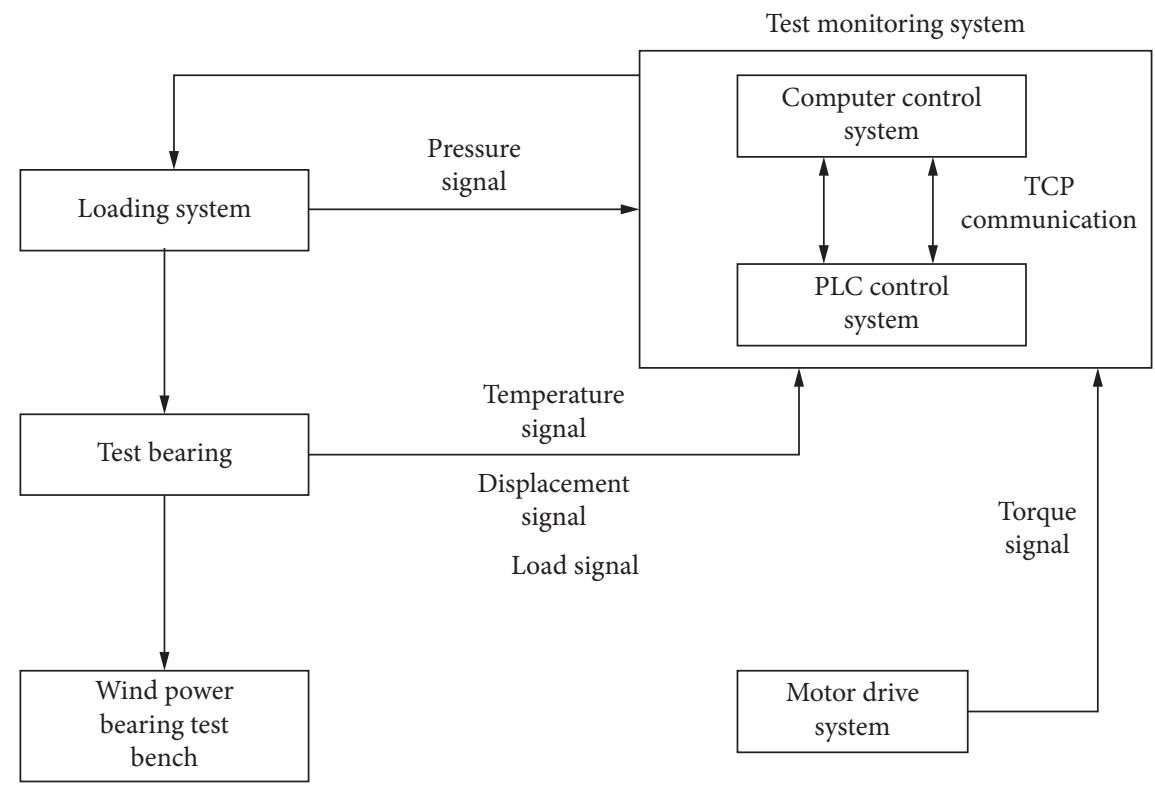

FIgURE 1: Schematic diagram of wind power bearing test bench.

\section{Performance Test Process of Wind Power Main Bearing Based on Test Bench}

4.1. Three-Dimensional Modeling of Test Bench. The overall structure of the wind power bearing loading test bench is shown in Figure 2. The overall structure of the test bench includes the flip component, the loading component, the underframe component, the moving component, the test bearing, and the driving component.

4.2. The Main Part of the Test Bench. The bearing component is the main part of the wind turbine bearing testing bench, which includes the tested bearing, test shaft, and gearbox and its sensor; the three-dimensional and physical drawings of the bearing part are shown in Figure 3. The basic structure of the main body of the test bench is an inner and outer double shaft system, in which the inner ring shaft system is stationary and the outer ring shaft system rotates. Both the test bearing and the accompany test bearing are single-row tapered roller bearings, which are installed symmetrically on the front end and the far end of the outer ring shaft system to achieve bidirectional fixation. After loading the test bearing, the sensor installed on the bearing will measure the various parameter values of the bearing. The transmission system of the testing bench is composed of AC motor, reducer, transmission gear box, universal joint, and transmission shaft. The universal joint is in direct contact with the bearing to be tested, ensuring reliable transmission of power energy, and has the function of buffering and damping. The driving force is provided by the AC motor to drive the test body to rotate, the motor speed can reach up to $1500 \mathrm{r} / \mathrm{min}$, and the test bearing speed can reach up to $30 \mathrm{r} / \mathrm{min}$. A torque sensor and a speed sensor are connected between the motor and the gearbox, and the computer control system can detect the torque and speed changes during the rotation of the tested bearing in real time.
4.3. Loading System. In order to simulate the real wind load of the wind power main bearing, a hydraulic loading system is selected to load the bearing. The loading system is mainly composed of 4 radial force loading cylinders and 4 axial force loading cylinders. The pressure of each cylinder is independently controlled by the PLC system, and the combination of various loads under different test requirements can be realized through the instructions issued by the PLC. The output pressure of the oil cylinder forms a closed loop with the PID through the pressure sensor to ensure that the output pressure of the oil cylinder is within the test setting range. The main technical indicators of the loading system are as follows: the maximum system pressure is $28 \mathrm{MPa}$; the maximum system flow is $200 \mathrm{~L} / \mathrm{min}$; and the load control accuracy is $\pm 2 \%$ F.S.

The hydraulic principle of a single cylinder is shown in Figure 4. When working, the PLC control system sends corresponding instructions to the loading system. The hydraulic oil enters the hydraulic cylinder through the solenoid valve, high-pressure oil filter, servo valve, and overflow valve in turn, pushing the cylinder to apply load to the test bearing. The accumulator provides the pressure holding performance of the oil cylinder to ensure the constant pressure of the hydraulic cylinder. At the same time, the position sensor and force sensor on the cylinder can accurately feed back the data to the test control system and then obtain the applied pressure and displacement characteristics of the test bearing.

4.4. Hydraulic Drive System. According to the development requirements of the test bench, the tested bearing can collect various data under the condition of simulating wind loading. The driving power is provided by the hydraulic oil pump driven by a $380 \mathrm{~V}$ servo AC motor. The speed of the motor can reach up to $960 \mathrm{r} / \mathrm{min}$, and the power of the hydraulic oil pump is $45 \mathrm{KW}$. The hydraulic principle of the hydraulic drive system is shown in Figure 5. 


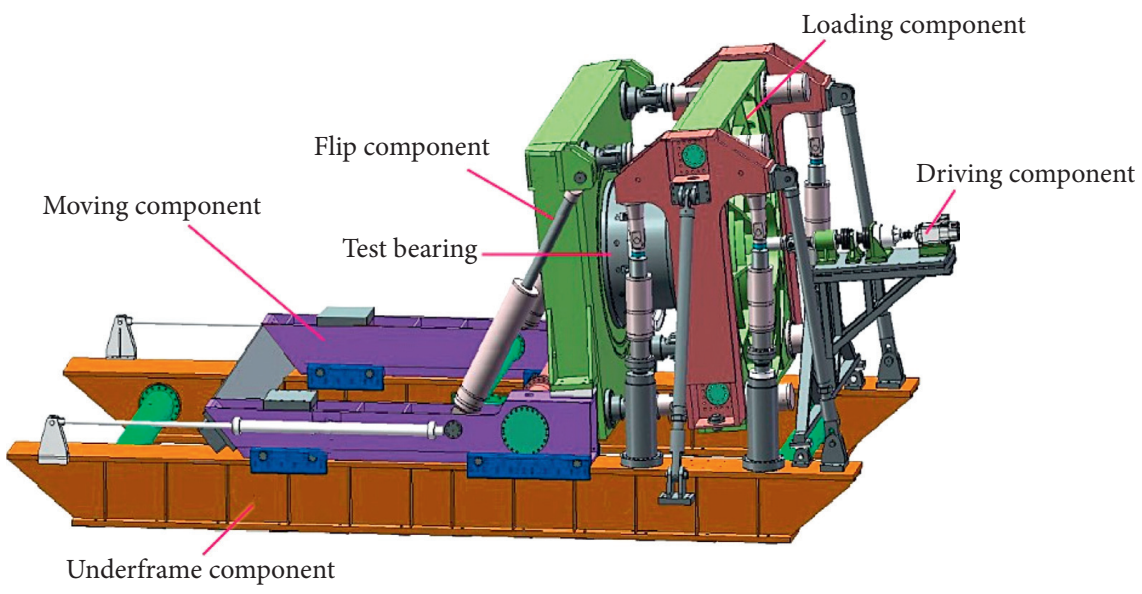

Figure 2: Overall structure of bearing test bench.

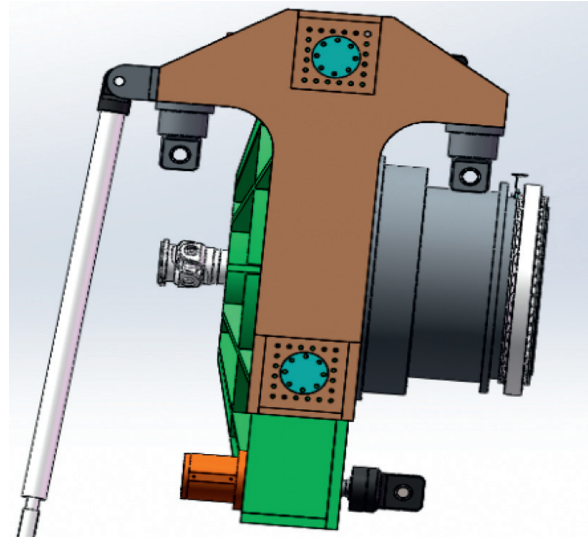

(a)

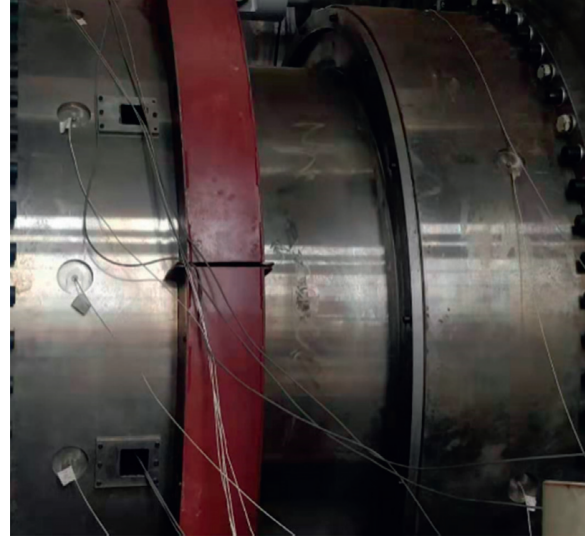

(b)

Figure 3: Bearing component. (a) Three-dimensional. (b) Physical map.

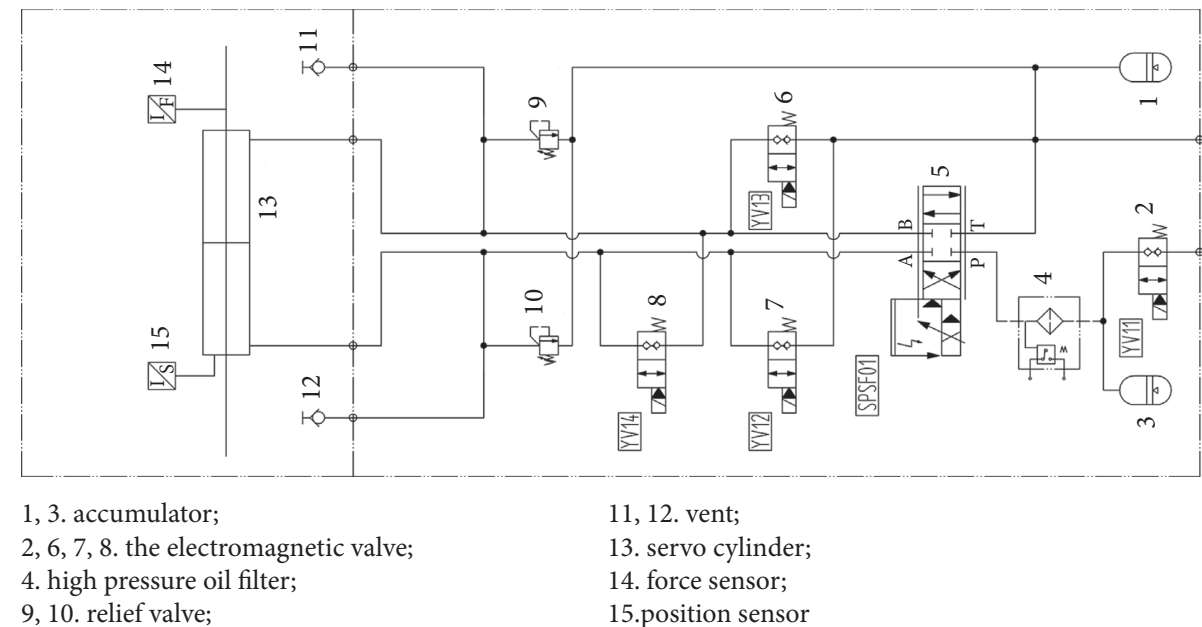

Figure 4: Hydraulic schematic diagram of a single cylinder.

4.5. Test Monitoring System. The test monitoring system includes two parts: PLC control system and computer monitoring system. Its system block diagram is shown in Figure 6. The PLC control system is composed of a PLC console, a PLC control cabinet, a programming controller, a contactor, buttons, etc. It can choose different types of modules, which can realize analog and digital input and output. In addition, it can control the magnitude and 


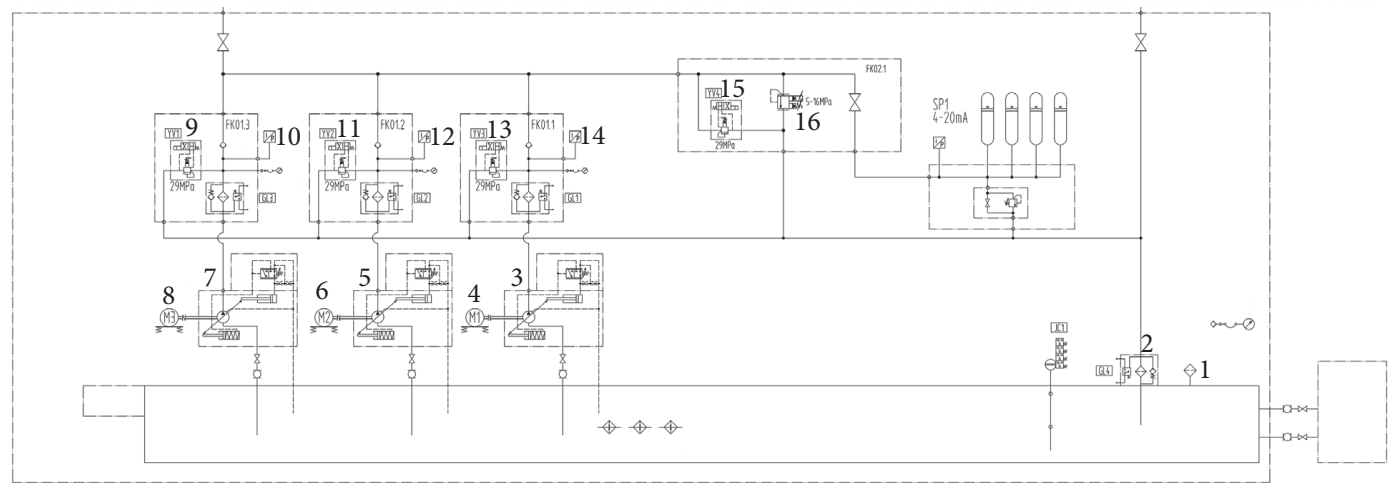

1. air filter;

2. return oil filter;

$3,5,6$. plunger pump;

4, 6, 8. Motor;
$10,12,14,17$. pressure transmitters;

$9,11,13,15$. electromagnetic relief valve;

16. proportional relief valve;

18. accumulator control valve;

Figure 5: Hydraulic principle diagram of hydraulic drive system.

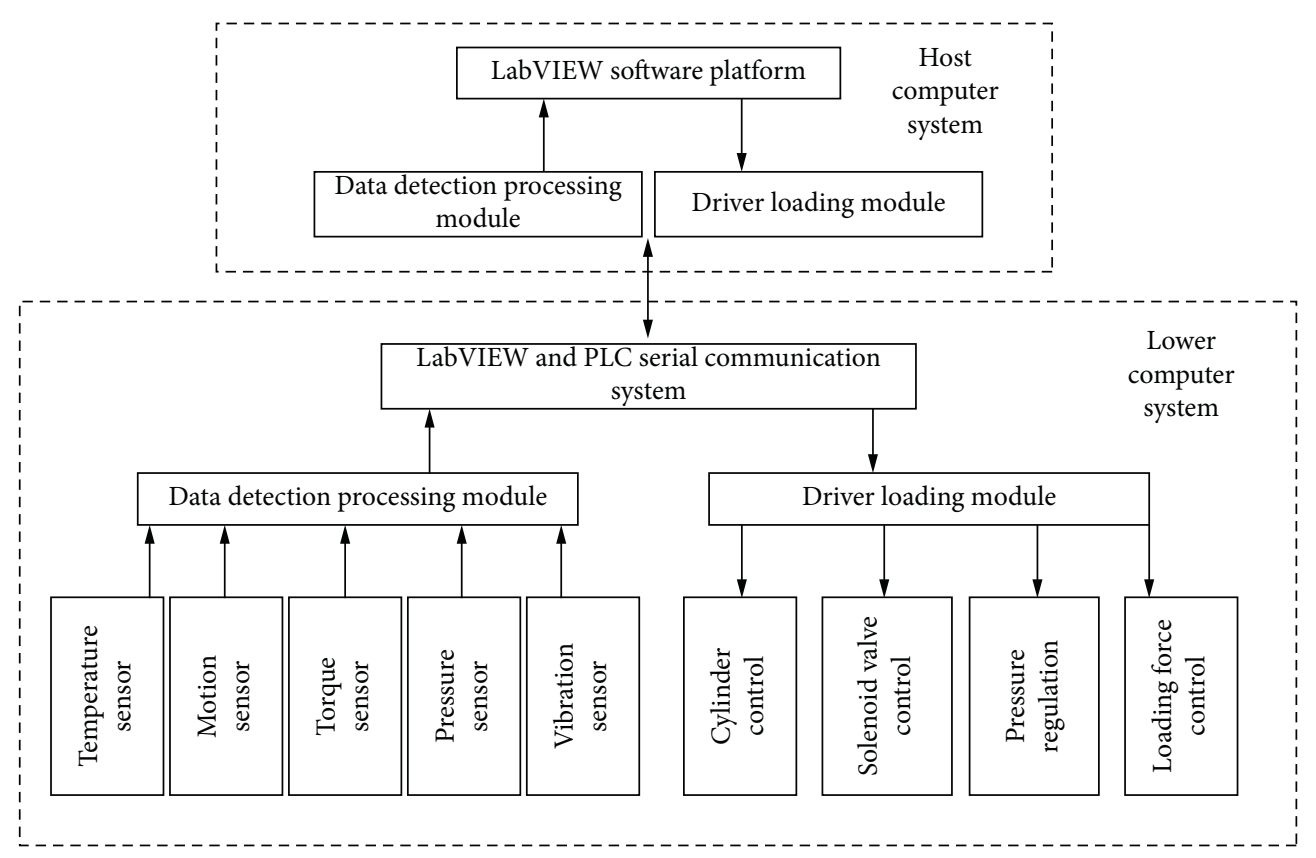

FIGURE 6: Block diagram of measurement and control system for wind power main bearing test bench.

direction of the load applied to the test body, as well as the function of controlling the test machine to replace the test bearing. It has two control modes: automatic loading and manual loading, which can quickly and accurately switch between the two. The manual loading method is mainly used in the debugging stage. It can apply load to each axis individually and control the size of the applied load manually. The automatic loading includes three methods: axial automatic loading, radial automatic loading, and overall automatic loading. The automatic loading of 4 axial forces, 4 radial forces, and 8 overall forces can be realized through the preset load size. At the same time, it can also control the movement and turnover of the test bench components. The PLC control system has high automation and loading accuracy and has advanced functions such as automatic accident alarm and emergency stop, which can realize unmanned operation and improve the reliability of wind power bearing test.

The computer control system consists of a data acquisition platform, a data acquisition cabinet, sensors, computers, test software, etc. The test system operation page is shown in Figure 7. It can control the start/stop of the motor and the adjustment of the test speed and accurately collect and process the data obtained from the sensor on the wind turbine bearing so as to realize the display of various parameters, alarm and protection functions. According to the test requirements, the computer control should accurately measure and process the temperature, displacement, load, and torque changes of the wind turbine bearing during the test. The temperature change mainly refers to the relative temperature difference between the inner and outer rings of the test bearing and the accompany test bearing. The inner 
ring temperature sensor is placed in the inner ring end, and the outer ring temperature sensor is placed on the outer ring end surface, which can measure the inner and outer ring temperature of the test bearing and the accompany test bearing. The displacement change mainly refers to the relative deformation of the inner and outer rings, which is completed by the displacement sensor, and they are, respectively, placed on the inner and outer rings of the test body. The real-time load can be obtained by the pressure sensor on the hydraulic cylinder. The monitoring system can record the torque when the driving system drives the test body to rotate in real time, which can be completed by the torque sensor.

4.6. Analysis of Mechanical Model of Wind Power Bearing. For fans with single-row tapered roller bearings, the force model of single-row tapered roller bearings is shown in Figure 8. It can be seen from the figure that when the distance between the fan hub and the reference surface of the tested bearing $\mathrm{A}$ is equal to $\mathrm{L} 0$, and the distance between the tested bearing $A$ and the tested bearing $B$ is equal to L1; when calculating the load, the load on the hub center can be loaded and converted to the tested bearing $\mathrm{A}$ and the tested bearing B. And according to the actual load after conversion, the actual loaded axial cylinder and radial cylinder are determined. The mechanical conversion equation is as follows:

Synthesize to the $X$ axis $\sum F_{X}$ :

$$
F_{X}=F_{X 0}
$$

Synthesize to the $Y$ axis $\sum F_{Y}$ :

$$
F_{Y}=F_{Y 0} \text {. }
$$

Synthesize to the $Z$ axis $\sum F_{Z}$ :

$$
F_{Z}=F_{Z 0} \text {. }
$$

Moment synthesis to the $Y$ axis $\sum M_{Y}$ :

$$
M_{Y}=M_{Y 0}+F_{Z 0} \cdot L_{0} \text {. }
$$

Moment synthesis to the $Y$ axis $\sum M_{Z}$ :

$$
M_{Z}=-F_{Y 0} \cdot L_{0}+M_{Z 0} \text {. }
$$

From the mechanical loading process, the LTS equivalent load and the ultimate load conversion calculation results of the $5 \mathrm{MW}$ wind turbine hub center are shown in Table 1.

The test bench adopts the coordinated loading method of axial and radial cylinders. The four cylinders in the axial direction and the four cylinders in the radial direction will be used as a dynamic system to load the test bearing. The center distance of the axial cylinder is $5 \mathrm{~m}$ and the center distance of the radial cylinder is $5 \mathrm{~m}$. The loading model is shown in Figure 9. The force balance equation of the loading cylinder is as follows:

$$
\begin{aligned}
& F_{a}=x_{1}, \\
& F_{b}=x_{2}, \\
& F_{c}=x_{3}, \\
& F_{d}=x_{4}, \\
& F_{e}=x_{5}, \\
& F_{f}=x_{6}, \\
& F_{g}=x_{7}, \\
& F_{h}=x_{8}, \\
& -\sin \alpha x_{1}-\sin \alpha x_{2}-\sin \alpha x_{3}-\sin \alpha x_{4}+x_{5}+x_{6}+x_{7}+x_{8}=F_{x}-G \cdot \sin \alpha \\
& \cos \alpha x_{1}+\cos \alpha x_{2}+\cos \alpha x_{3}+\cos \alpha x_{4}=F_{Z 0}+G \cdot \cos 5^{\circ}, \\
& \left(L_{4} \cdot \cos \alpha-L_{2} \cdot \sin \alpha\right) \cdot x_{1}+\left(L_{4} \cdot \cos \alpha-L_{2} \cdot \sin \alpha\right) \cdot x_{2}+\left(L_{3} \cdot \cos \alpha-L_{2} \cdot \sin \alpha\right) \cdot x_{3} \\
& +\left(L_{3} \cdot \cos \alpha-L_{2} \cdot \sin \alpha\right) \cdot x_{4}+L_{5} \cdot x_{5}+L_{5} \cdot x_{6}-L_{5} \cdot x_{7}- \\
& L_{5} \cdot x_{8}=M_{Y 0}+F_{Z 0} \cdot L_{0}-G \cdot \sin 5^{\circ}, \\
& 2.5 x_{5}-2.5 x_{6}+2.5 x_{7}-2.5 x_{8}=M_{Z 0}-F_{Y 0} \cdot L_{0}, \\
& x_{1}-x_{2}=0, \\
& x_{3}-x_{4}=0,
\end{aligned}
$$




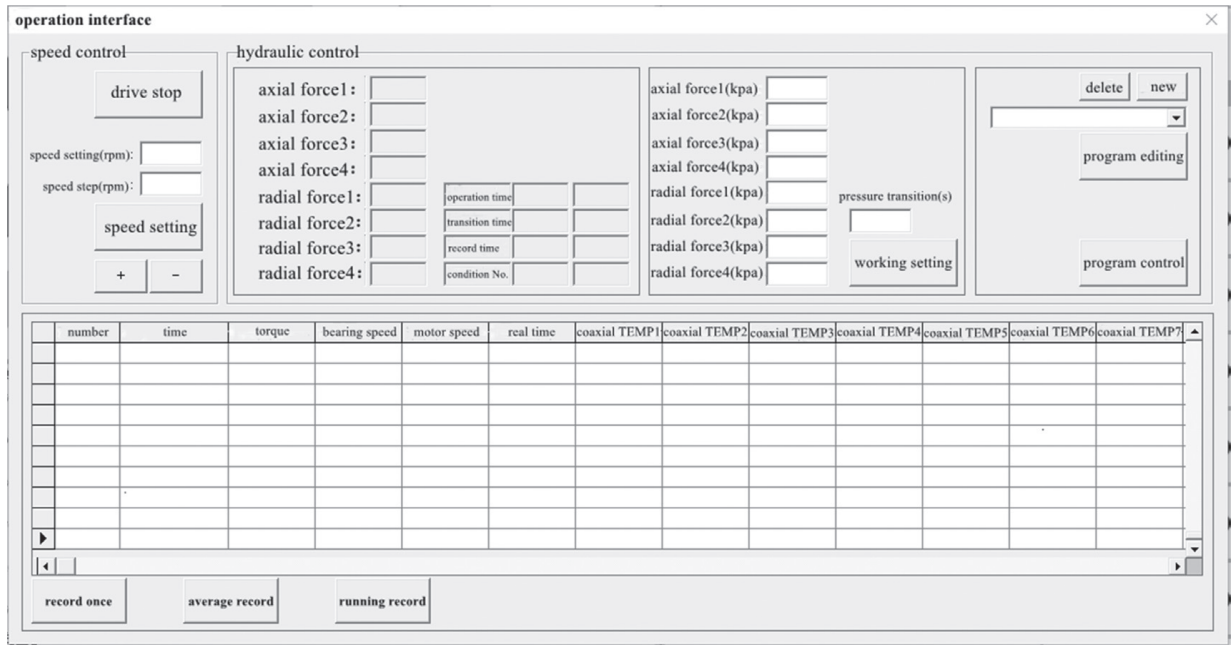

Figure 7: Test system operation interface.

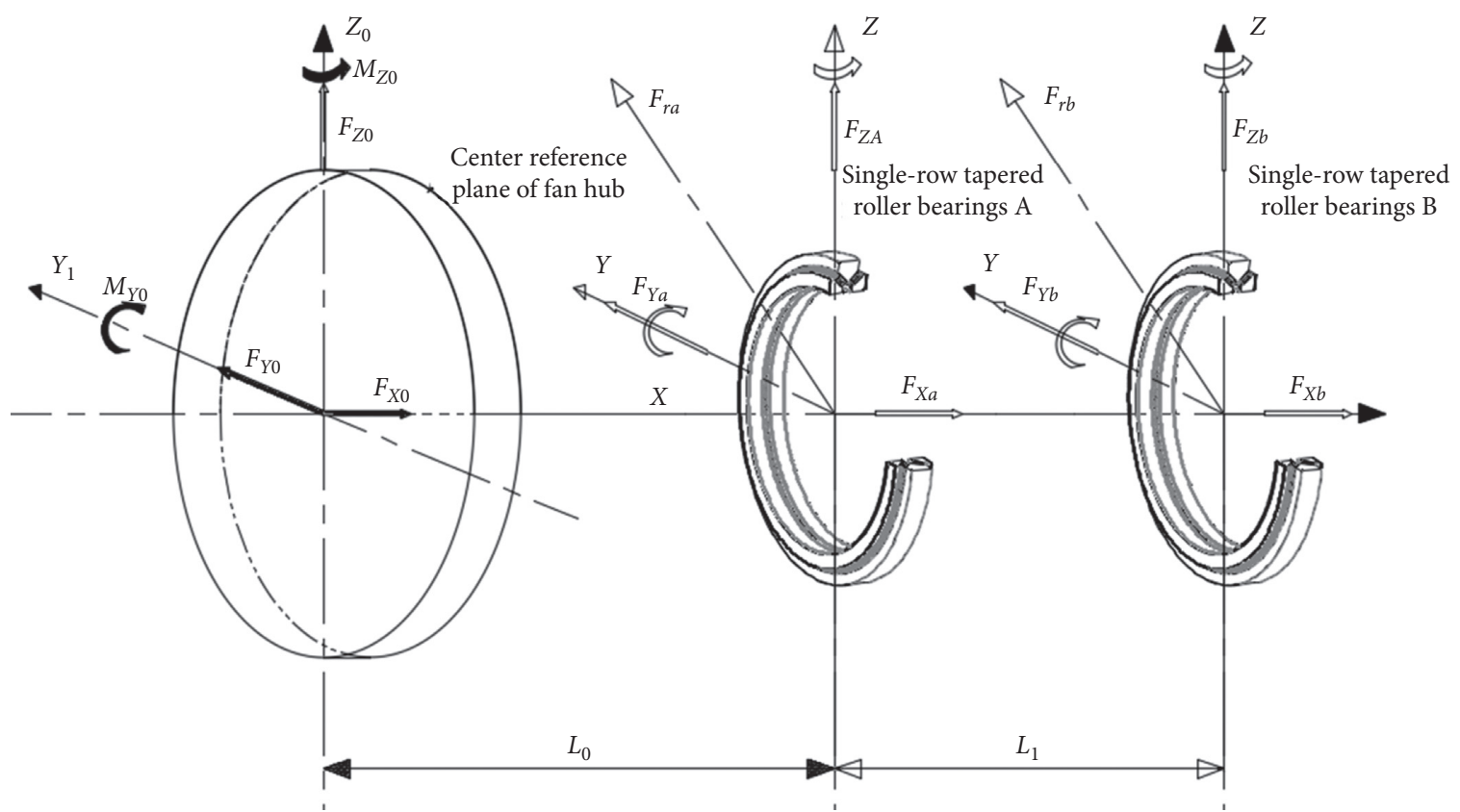

FIgURE 8: Mechanical model of single-row tapered roller bearing.

where

$$
\begin{aligned}
\alpha & =5^{\circ}, \\
L_{0} & =1.61 \mathrm{~m}, \\
L_{1} & =1.34 \mathrm{~m}, \\
L_{2} & =1.28 \mathrm{~m}, \\
L_{3} & =0.86 \mathrm{~m}, \\
L_{4} & =3.46 \mathrm{~m}, \\
L_{5} & =2.5 \mathrm{~m}, \\
L_{6} & =1.916 \mathrm{~m}, \\
L_{7} & =0.309 \mathrm{~m} .
\end{aligned}
$$

Putting the data in Table 1 into the above equation, the cylinder loading data of the $5 \mathrm{MW}$ wind turbine main shaft bearing test bench can be obtained, as shown in Table 2 .

4.7. Test Results and Discussion. In order to verify the technical performance indicators and reliability of the wind power bearing testing machine, a comprehensive assessment test was carried out on the testing machine. The specific test conditions are as follows: Both the test bearing and the accompany test bearing are single-row tapered roller bearings with an outer diameter of $2500 \mathrm{~mm}$, an inner diameter of $2000 \mathrm{~mm}$, and a height of $320 \mathrm{~mm}$. Bearing test speed is $15 \mathrm{r} / \mathrm{min}$, and motor test speed is $750 \mathrm{r} / \mathrm{min}$. The axial and radial loading loads are shown in Table 2. 
TABLE 1: $5 \mathrm{MW}$ tested bearing load table.

\begin{tabular}{lccccc}
\hline & $F_{x}(\mathrm{KN})$ & $F_{y}(\mathrm{KN})$ & $F_{z}(\mathrm{KN})$ & $M_{z}(\mathrm{KNm})$ & -2223.443 \\
\hline LRD equivalent load & 667.4 & -23.1 & -1301 & $M_{y}(\mathrm{KNm})$ \\
Ultimate load & 202 & -287.5 & -1711.2 & 18369.958 & 2508.723 \\
\hline
\end{tabular}

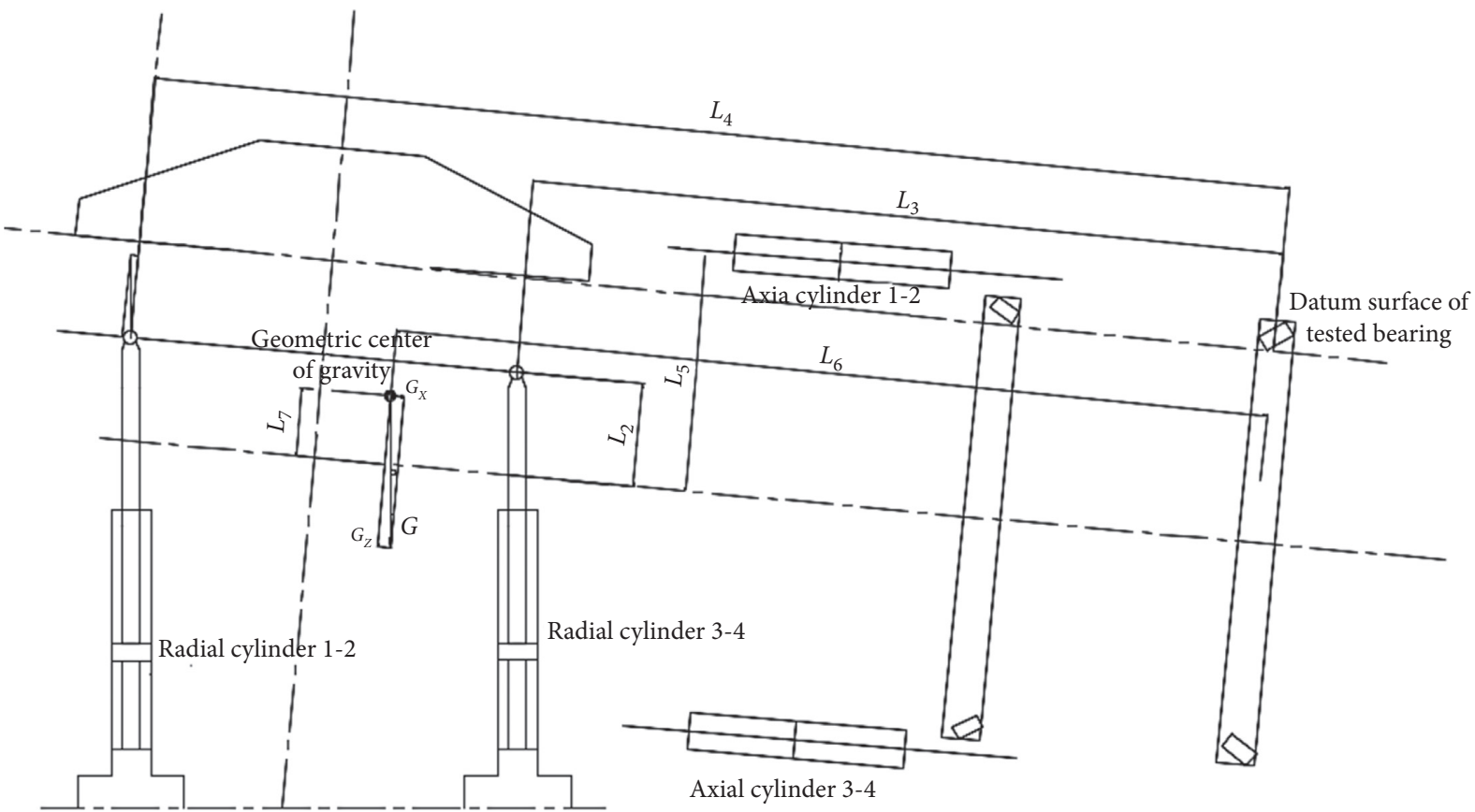

FIgURE 9: Cylinder loading model diagram.

TABle 2: Load data of cylinder of test bench.

\begin{tabular}{lcccccccc}
\hline & \multicolumn{4}{c}{ Radial cylinder } & \multicolumn{3}{c}{ Axial cylinder } \\
\hline Cylinder load & No. 3 (KN) & No. 1 (KN) & No. 4 (KN) & No. 2 (KN) & No. 1 (KN) & No. 2 (KN) & No. 3 (KN) & No. 4 (KN) \\
Equivalent load & 847 & 847 & -300 & -300 & 1149 & -1430 & -855 & 1400 \\
Ultimate load & 768 & 768 & -300 & -300 & 1746 & -559 & -2542 & 1400 \\
\hline
\end{tabular}

After the testing machine runs smoothly, the performance indicators of the wind power bearing are analyzed, and the test results are shown in Figure 10. It can be seen from the test results that the temperature of the tested bearing and the test bearing are maintained within the normal range. The torque is stable, the output pressure of the loading system is stable, and the test machine runs stably. The deformation of axial displacement and radial displacement are both within $5 \mathrm{~mm}$, which is within the range required by the experiment. The measurement and control system is working normally, the test data is true and effective, the control is highly accurate, various predetermined functions are successfully realized, and a certain evaluation can be given to the life and running status of the tested bearing.

\section{Comparison with the Old Technique}

(1) In view of the inability to apply overturning pressure to the wind turbine bearing, the small number of collected data signals cannot truly reflect the actual working conditions of the wind turbine bearing, and the lack of automation level of the old measurement and control system, this paper presents a measurement and control system for wind turbine bearing testing machine based on LabVIEW and PLC. Multistage hydraulic loading control is realized through PID control principle and loop nesting between programs, and the data loading is stable and reliable. The data monitoring and processing module mainly completes the collection and processing of test data under the driving load of the test bearing and real-time monitoring of the loading process. It can monitor the temperature, displacement, and torque changes of the tested bearing during the loading process in real time. It has the functions of automatic accident alarm and emergency stop, high automation level, low development cost, and high engineering application value.

(2) Aiming at the defect of poor load simulation function, this paper proposes a mathematical model of wind turbine bearing loading. Using the relevant analysis method of the space force system 


\begin{tabular}{|c|c|c|c|c|c|}
\hline Measuring torque (N.m) & -9842 & Measuring speed $(\mathrm{r} / \mathrm{min})$ & 15 & Motor speed (s) & 750 \\
\hline Bearing radius $(\mathrm{m})$ & 2.5 & Real time (s) & & & 1946 \\
\hline Outer shaft TEMP01 $\left({ }^{\circ} \mathrm{C}\right)$ & 19.9 & Shaft TEMP01 $\left({ }^{\circ} \mathrm{C}\right)$ & 18.1 & Coaxial TEMP01 $\left({ }^{\circ} \mathrm{C}\right)$ & 20.1 \\
\hline Outer shaft TEMP02 $\left({ }^{\circ} \mathrm{C}\right)$ & 20.0 & Shaft TEMP02 $\left({ }^{\circ} \mathrm{C}\right)$ & 17.8 & Coaxial TEMP02 $\left({ }^{\circ} \mathrm{C}\right)$ & 20.1 \\
\hline Outer shaft TEMP03 $\left({ }^{\circ} \mathrm{C}\right)$ & 20.4 & Shaft TEMP03 $\left({ }^{\circ} \mathrm{C}\right)$ & 18.1 & Coaxial TEMP03 $\left({ }^{\circ} \mathrm{C}\right)$ & 20.2 \\
\hline Outer shaft TEMP04 $\left({ }^{\circ} \mathrm{C}\right)$ & 20.5 & Shaft TEMP04 $\left({ }^{\circ} \mathrm{C}\right)$ & 18.3 & Coaxial TEMP04 $\left({ }^{\circ} \mathrm{C}\right)$ & 20.2 \\
\hline Outer shaft TEMP05 $\left({ }^{\circ} \mathrm{C}\right)$ & 20.1 & Shaft TEMP05 $\left({ }^{\circ} \mathrm{C}\right)$ & 18.0 & Coaxial TEMP05 $\left({ }^{\circ} \mathrm{C}\right)$ & 19.9 \\
\hline Outer shaft TEMP06 $\left({ }^{\circ} \mathrm{C}\right)$ & 19.9 & Shaft TEMP06 $\left({ }^{\circ} \mathrm{C}\right)$ & 18.4 & Coaxial TEMP06 $\left({ }^{\circ} \mathrm{C}\right)$ & 20.0 \\
\hline Outer shaft TEMP07 $\left({ }^{\circ} \mathrm{C}\right)$ & 20.0 & Shaft TEMP07 $\left({ }^{\circ} \mathrm{C}\right)$ & 17.9 & Coaxial TEMP07 $\left({ }^{\circ} \mathrm{C}\right)$ & 20.1 \\
\hline Outer shaft TEMP08 $\left({ }^{\circ} \mathrm{C}\right)$ & 20.5 & Shaft TEMP08 $\left({ }^{\circ} \mathrm{C}\right)$ & 18.5 & Coaxial TEMP08 $\left({ }^{\circ} \mathrm{C}\right)$ & 20.3 \\
\hline
\end{tabular}

(a)

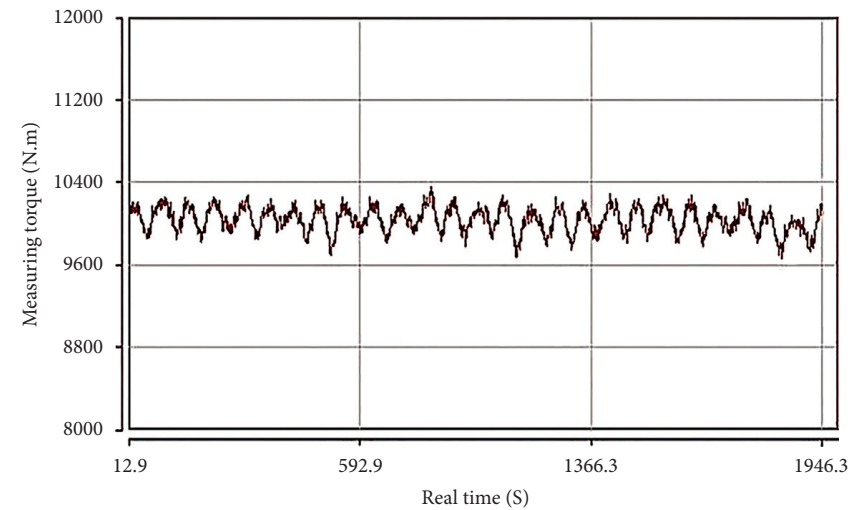

(b)

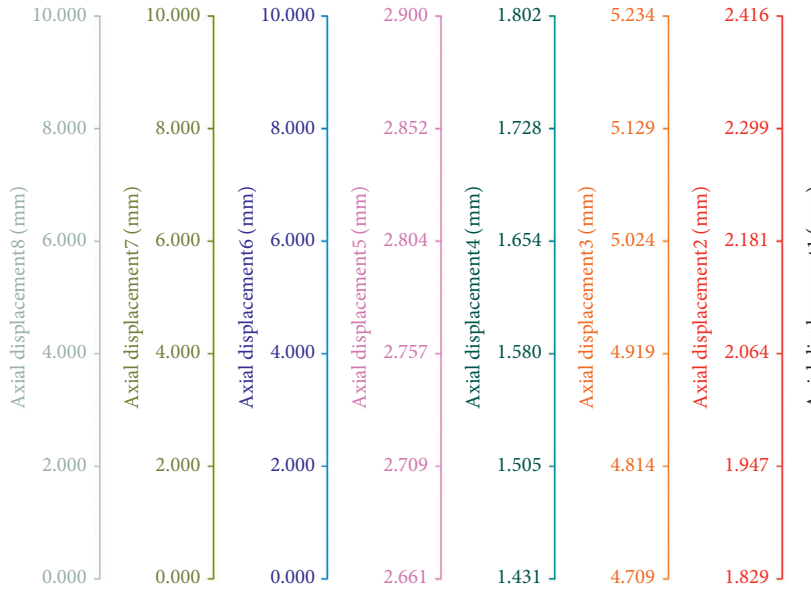

(c)

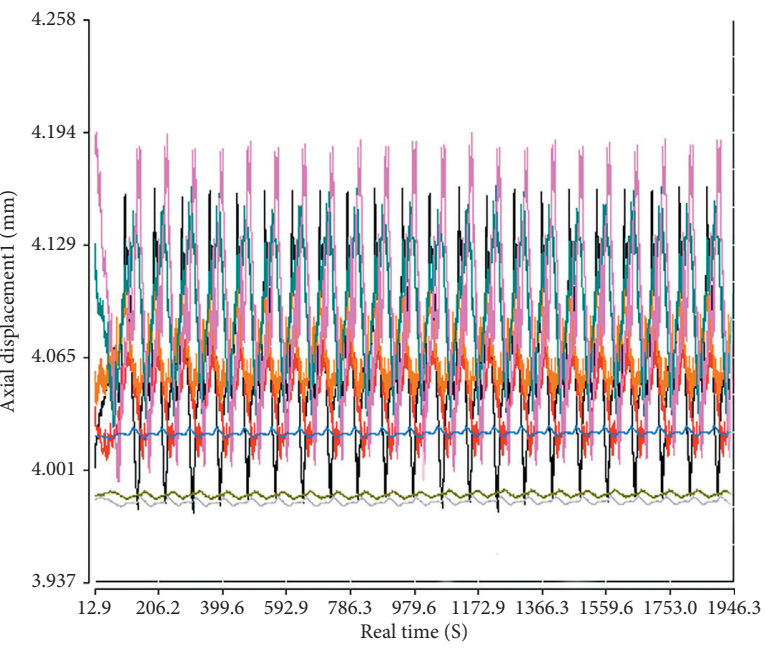

Figure 10: Continued. 


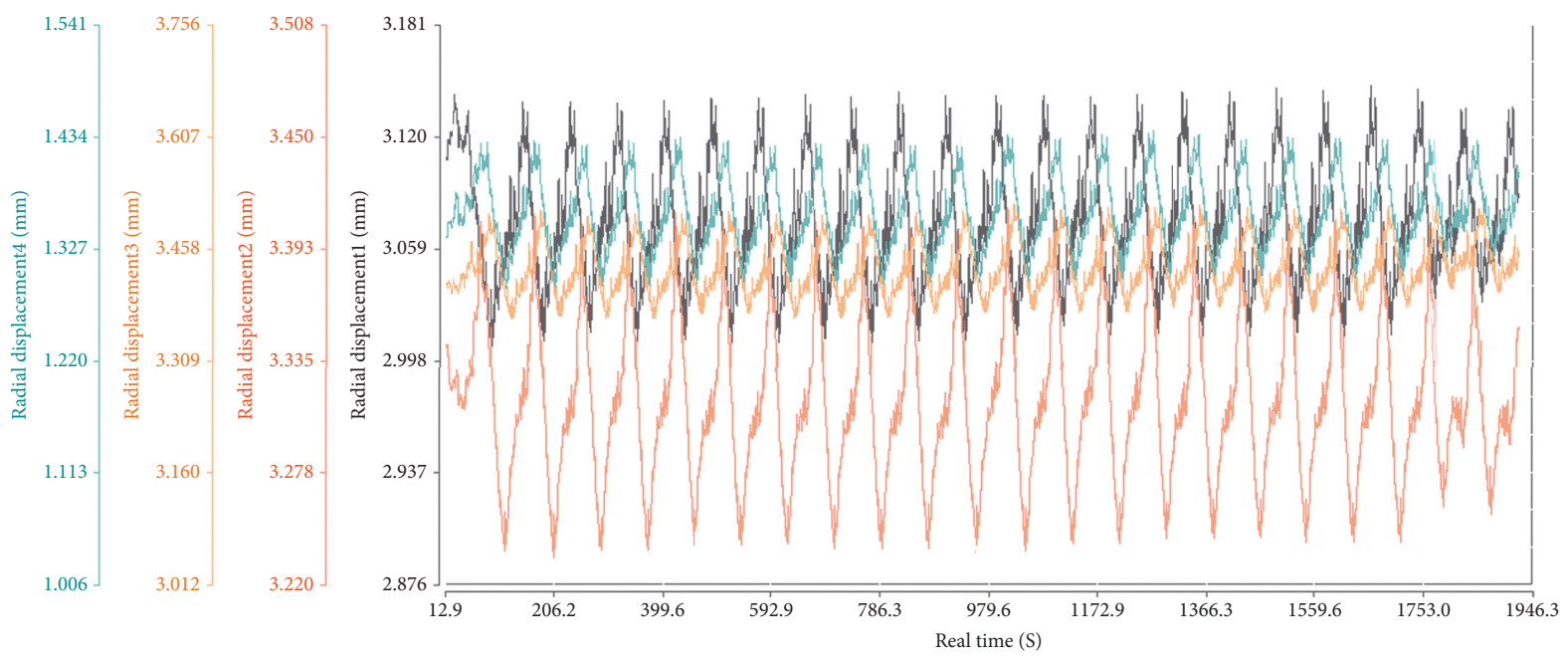

(d)

FIGURE 10: Test bearing test results. (a) Temperature interface. (b) Torque interface. (c) Radial displacement interface. (d) Axial displacement interface.

in engineering mechanics, the hub center load was converted to the measured bearing reference plane, and the force system conversion mathematical model was established to convert the hub center load into the axial cylinder load and radial cylinder load of the test bench. Load simulates the loading of the tested bearing, which can simulate the working environment of the main bearing of wind power in the most realistic manner, and realizes PID closed-loop feedback control for hydraulic loading, which can ensure free switching between different test conditions, and the loading value remains stable. It has the advantages of fast response speed, flexible signal processing, and interference suppression.

(3) In view of the troublesome characteristics of the traditional bearing testing machine to replace the bearings, the flip and move functions of the test bench components are designed. It is controlled by a PLC control system, which can easily replace test bearings and improve work efficiency.

\section{Conclusions and Future Work}

The test bench discussed in this article is the first $5 \mathrm{MW}$ wind power spindle bearing test bench in China. The solid modeling of the experimental platform was carried out using the 3D modeling software SolidWorks. Hydraulic loading system and test monitoring system are designed to realize the drive and control of the test bench. Through the established mathematical model, the load type and load size of the test bed on the tested bearing are determined, and the hub center load is converted into the axial cylinder load and radial cylinder load of the test bed to simulate loading of the tested bearing. The testing machine has reasonable design, complete functions, and high degree of automation. It can test the temperature, displacement, torque, load, and other performance parameters of wind turbine bearings under simulated real working conditions. At the same time, it can analyze the collected data, which satisfies the test requirements of wind power spindle bearings. At present, the wind power main shaft bearing test bed has been put into use in related enterprises, and it is operating in good condition, which has played a very good role in promoting the reliability and safety of the wind power industry.

In addition, our research methods are not perfect, and there are still some research contents that need to be further explored. Research is carried out on the weight, size, and welding process of the test bench. With the vigorous development of wind power technology, the single-unit capacity of wind turbines continues to increase, and the design and manufacture of bearing testing machines for higherpower wind turbines has become the subject of further research. PID control is not ideal for time-delay systems and nonlinear uncertain systems; therefore, combining the advantages of PID with advanced control methods such as neural network control is the future direction of traditional PID control.

\section{Abbreviations}

$F_{x}$ : Load in the $X$-axis direction of the hub center $(\mathrm{N})$

$F_{y}$ : Load in the $Y$-axis direction of the hub center $(\mathrm{N})$

$F_{z}$ : Load in the $Z$-axis direction of the hub center $(\mathrm{N})$

$L_{0}$ : The distance between the center of the wind turbine hub and the reference surface of the test bearing (m)

$L_{1}$ : The distance between the tested bearing $\mathrm{A}$ and the tested bearing B (m).

\section{Data Availability}

All data and models generated or used during the study are included within the article. 


\section{Conflicts of Interest}

The authors declare that they have no conflicts of interest regarding the publication of this paper.

\section{Acknowledgments}

This work was financially supported by the National Training Program of Innovation and Entrepreneurship for Undergraduates (Grant no. 202011413034), the Fundamental Research Funds for the Central Universities (Grant no. 2020YJSJD06), the Cross Training Program of HighLevel Talents in Beijing University (Grant no. 2019114132316), and the Teaching Reform Project of China University of Mining and Technology-Beijing (Grant nos. J200518 and J20ZD17).

\section{References}

[1] H. Muhsen, W. AL-Kouz, and W. khan, "Small wind turbine blade design and optimization," Symmetry, vol. 12, no. 1, p. 18, 2020.

[2] M. Ebrahimpour, R. Shafaghat, R. Alamian, and M. Safdari Shadloo, "Numerical investigation of the savonius vertical axis wind turbine and evaluation of the effect of the overlap parameter in both horizontal and vertical directions on its performance," Symmetry, vol. 11, no. 6, p. 821, 2019.

[3] J. Wang, S. Zhou, Z. Zhang, and D. Yurchenko, "High-performance piezoelectric wind energy harvester with $Y$-shaped attachments," Energy Conversion and Management, vol. 181, pp. 645-652, 2019.

[4] B. Yang, T. Yu, H. Shu, J. Dong, and L. Jiang, "Robust slidingmode control of wind energy conversion systems for optimal power extraction via nonlinear perturbation observers," Applied Energy, vol. 210, pp. 711-723, 2018.

[5] X. Wu, "Current status and technical development trend of wind power generation in my country," Tendering \& Purchasing Management, vol. 44, p. 225, 2017.

[6] Y. Zhao, L. Ye, Z. Li, X. Song, Y. Lang, and J. Su, "A novel bidirectional mechanism based on time series model for wind power forecasting," Applied Energy, vol. 177, pp. 793-803, 2016.

[7] X. Wang, P. Guo, and X. Huang, "A review of wind power forecasting models," Energy Procedia, vol. 12, pp. 770-778, 2011.

[8] S. Sawyer, L. M. Qiao, and L. Fried, Global Wind Report: Annual Market Update 2017, GWEC, Global Wind Energy Council, Brussels, Belgium, 2017.

[9] Y. Xiao, N. Kang, Y. Hong, and G. Zhang, "Misalignment fault diagnosis of DFWT based on IEMD energy entropy and PSOSVM," Entropy, vol. 19, no. 1, p. 6, 2017.

[10] Z. P. Liu and L. Zhang, "A review of failure modes, condition monitoring and fault diagnosis methods for large-scale wind turbine bearings," Measurement: Journal of the International Measurement Confederation, vol. 149, Article ID 107002, 2020.

[11] C. Su and Z. Hu, "Reliability assessment for Chinese domestic wind turbines based on data mining techniques," Wind Energy, vol. 21, no. 3, pp. 198-209, 2018.

[12] Y. L. Dong, Y. Q. Li, and H. B. Cao, "Real-time health condition evaluation on wind turbines based on operational condition recognition," Proceedings of the CSEE, vol. 33, no. 11, pp. 88-95, 2013.
[13] X. Xu and X. Liu, "Weak characteristic information extraction from early fault of wind turbine generator gearbox," Frontiers of Mechanical Engineering, vol. 12, no. 3, pp. 357-366, 2017.

[14] H. Li, Y. Li, Y. Hu, and D. Yang, "Overview of condition monitoring and fault diagnosis for grid-connected highpower wind turbine unit," Electric Power Automation Equipment, vol. 36, no. 1, pp. 6-16, 2016.

[15] H. Sun, C. Qiu, L. Lu, X. Gao, J. Chen, and H. Yang, "Wind turbine power modelling and optimization using artificial neural network with wind field experimental data," Applied Energy, vol. 280, Article ID 115880, 2020.

[16] A. Iqbal, D. Ying, A. Saleem, M. A. Hayat, and M. Mateen, "Proposed particle swarm optimization technique for the wind turbine control system," Measurement and Control, vol. 53, no. 5-6, pp. 1022-1030, 2020.

[17] B. Han, L. Zhou, F. Yang, and Z. Xiang, "Individual pitch controller based on fuzzy logic control for wind turbine load mitigation," IET Renewable Power Generation, vol. 10, no. 5, pp. 687-693, 2016.

[18] A. Iqbal, D. Ying, A. Saleem, M. A. Hayat, and K. Mehmood, "Efficacious pitch angle control of variable-speed wind turbine using fuzzy based predictive controller," Energy Reports, vol. 6, pp. 423-427, 2020.

[19] Y. Guo, S. Sheng, C. Phillips et al., "A methodology for reliability assessment and prognosis of bearing axial cracking in wind turbine gearboxes," Renewable and Sustainable Energy Reviews, vol. 127, Article ID 109888, 2020.

[20] M. Rezamand, M. Kordestani, R. Carriveau, D. S.-K. Ting, and M. Saif, "An integrated Feature-Based failure prognosis method for wind turbine bearings," IEEE/ASME Transactions on Mechatronics, vol. 25, no. 3, pp. 1468-1478, 2020.

[21] Y. Kong, T. Wang, Z. Feng, and F. Chu, "Discriminative dictionary learning based sparse representation classification for intelligent fault identification of planet bearings in wind turbine," Renewable Energy, vol. 152, pp. 754-769, 2020.

[22] X. Chen, W. Xu, Y. Liu, and M. R. Islam, "Bearing corrosion failure diagnosis of doubly fed induction generator in wind turbines based on stator current analysis," IEEE Transactions on Industrial Electronics, vol. 67, no. 5, pp. 3419-3430, 2020.

[23] Q. Xu, Z. Fan, W. Jia, and C. Jiang, "Quantile regression neural network-based fault detection scheme for wind turbines with application to monitoring a bearing," Wind Energy, vol. 22, no. 10, pp. 1390-1401, 2019.

[24] Y. Guo, Z. Zhao, R. Sun, and X. Chen, "Data-driven multiscale sparse representation for bearing fault diagnosis in wind turbine," Wind Energy, vol. 22, no. 4, pp. 587-604, 2019.

[25] X. Gu and C. Chen, "Adaptive parameter-matching method of SR algorithm for fault diagnosis of wind turbine bearing," Journal of Mechanical Science and Technology, vol. 33, no. 3, pp. 1007-1018, 2019.

[26] J. Wang, Y. Liang, Y. Zheng, R. X. Gao, and F. Zhang, "An integrated fault diagnosis and prognosis approach for predictive maintenance of wind turbine bearing with limited samples," Renewable Energy, vol. 145, pp. 642-650, 2020.

[27] S. Nath, J. Wu, Y. Zhao, and W. Qiao, "Low latency bearing fault detection of direct-drive wind turbines using stator current," IEEE ACCESS, vol. 8, pp. 44163-44174, 2020.

[28] J. W. Han, J. S. Nam, Y. J. Park, G. H. Lee, and Y. Y. Nam, “An experimental study on the performance and fatigue life of pitch bearing for wind turbine," Journal of Mechanical Science and Technology, vol. 29, no. 5, pp. 1963-1971, 2015.

[29] Z. H. Liu, "Test method and test platform for pitch bearing in wind turbine generator set," Chia Patent CN200810119118.0, 2009. 
[30] Y. B. Tang, Y. Zeng, and H. X. Li, "Pitch motor and pitch bearing test equipment of wind power generator," Chia Patent CN201020205747.8, 2010.

[31] J. Liu, "Measurement of friction torque of wind power pitch bearing," Bearing, vol. 06, pp. 42-44, 2011.

[32] L. J. Wu, G. S. Zeng, and T. H. Yu, "Wind turbine yaw test mechanism and wind turbine complete machine test bench," Chia Patent CN200810204572.6, 2009.

[33] S. Zupan, R. Kunc, and I. Prebil, "Experimental determination of damage to bearing raceways in rolling rotational connections," Experimental Techniques, vol. 30, no. 2, pp. 31-36, 2006.

[34] H. Hirani, "Root cause failure analysis of outer ring fracture of Four-Row cylindrical roller bearing," Tribology Transactions, vol. 52, no. 2, pp. 180-190, Article ID 9073819022, 2009.

[35] C. Zouhaier, "Screw behavior in large diameter slewing bearing assemblies:numerical and experimental analysis," International Journal on Interactive Design and Manufacturin, vol. 1, pp. 21-31, 2007.

[36] S. Kock, G. Jacobs, A. Hirt et al., "Robustness test for wind turbine gearbox bearingsJournal of Physics Conference Series," Journal of Physics Conference Series, vol. 1037, Article ID UNSP052012, 2018.

[37] S. Toyoda, N. Ohashi, H. Takiuchi, and K. Ueda, "Automatic calculation service device for bearing performance," JP20130102968, 2014. 